\title{
Cohesion in News Articles: A Discourse Analysis Approach
}

\author{
Angelina Subrayan Michael (corresponding author) \\ Academy of Language Studies, Universiti Teknologi MARA Shah Alam \\ 54000 Shah Alam, Malaysia \\ Tel: 012-4046762 E-mail: angiesubrayan@hotmail.com \\ Chittra Muthusamy \\ Academy of Language Studies, Universiti Teknologi MARA Shah Alam \\ 54000 Shah Alam, Malaysia \\ Tel: 012-3763231 E-mail: chitt911@tganu.uitm.edu.my \\ Puspalata C Suppiah \\ Academy of Language Studies, Universiti Teknologi MARA Shah Alam \\ 54000 Shah Alam, Malaysia \\ Tel: 019-3362848 E-mail: puspa_ts@yahoo.com \\ Caroline Joseph \\ Academy of Language Studies, Universiti Teknologi MARA Pahang Campus, \\ 26400, Bandar Tun Abdul Razak, Jengka pahang \\ Tel: 019-4642052 E-mail: carolinej@pahang.uitm.edu.my \\ Sulia Masturina binti Che Razali \\ Academy of Language Studies, Universiti Teknologi MARA \\ Terengganu Campus, \\ 23000 Dungun Terengganu, Malaysia \\ Tel: 019-9596876 E-mail: sulia@tganu.uitm.edu.my
}

Received: 16-02-2013

Accepted: 23-03-2013

Published: 01-05-2013

doi:10.7575/aiac.ijalel.v.2n.3p.129

URL: http://dx.doi.org/10.7575/aiac.ijalel.v.2n.3p.129

\begin{abstract}
Cohesion is deemed to be outside of the structure of text because structure in text is provided by grammar. The design of cohesion in text is connected to semantic ties or "relations of meanings that exist within the text, and that define it as a text" (Halliday and Hasan, 1976). The study discusses an analysis done on two Malaysian newspaper articles from the New Straits Times. The study investigates the discourses apparent in the texts and the methods in which discourses are represented through particular linguistic choices. The purpose of the study is to identify discourses that stand for universally held assumptions about how different texts are created and how these discourses signify connection of specific practices and/or encompass a policy for change. Halliday \& Hasan (1976) convey texture to the method in which diverse fundamentals in a text are connected or attached jointly to shape a cohesive unity, which also conveys the fact that the texts express completely to the setting in which it is located. Both articles project several connections in the field, in the theme and in the method of writing which are reflected in their corresponding ritual of structural and lexicogrammatical resources.
\end{abstract}

Keywords: cohesion, discourse analysis, reference, conjunction, lexical cohesion

\section{Introduction}

The study discusses an analysis done on two newspaper articles from the New Straits Times. The study investigates the discourses apparent in the texts and the methods in which discourses are represented through particular linguistic choices. The purpose of the study is to identify discourses that stand for universally held assumptions about how different texts are created and how these discourses signify connection of specific practices and/or encompass a policy for change. Halliday \& Hasan (1976) convey texture to the method in which diverse fundamentals in a text are connected or attached jointly to shape a cohesive unity, which also conveys the fact that the text expresses completely to the setting in which it is located.

The two sample texts chosen for analysis in this study are 'Five Kids need your help' in The Straits Times newspaper (Jan. 03, 2012), which is hereafter called Text A, and ' 2 kids need RM68, 000 for heart ops', The Straits Times (Dec. 22, 2011) and is called Text B. Article A reports the plea for donation for five children who are suffering from serious heart conditions. Similarly, article B reports on the same issue, but it involves two children. Both articles projects several connections in the field (i.e. they both are newspaper journalism appealing for donation), in the theme (i.e. the 
association involving addresser and addressee is that of writer and unspecified readership), and in the method (i.e. they are both newspaper articles). In addition, they take somewhat similar evaluative situations on their respective main protagonists, which are reflected in their corresponding ritual of structural and lexico-grammatical resources.

\section{Theoretical framework}

\subsection{Principles of Cohesion}

Cohesion is deemed to be outside of the structure of text because structure in text is provided by grammar. Researchers like Hassan and Halliday (1976) perceive that using linguistic ties formulate the text to be more cohesive and comprehensible. Cohesion means the "non-structural text-forming relations" (Halliday \& Hasan 1976: 7). The design of cohesion in text is connected to semantic ties or "relations of meanings that exist within the text, and that define it as a text" (Halliday and Hasan, 1976). Besides, if a previously stated item in the text is referred to another time and is dependent on one more component, it is measured a tie. Sentences or speech would appear to lack any type of association to each other and might not be regarded as text without semantic ties. Halliday and Hasan called this intertextual relation as "the presupposing" and "the presupposed".

Cohesion is a semantic asset of a text connecting in some way. A cohesive text has a tendency to link its sentences as one semantically. This semantic feature of cohesion has a connection with the reader who understands the elements in a particular co-text depending on the other element within the same co-text. Halliday and Hassan affirm that: "Cohesion occurs where the interpretation of some element in the discourse is dependent on that of another. The one presupposes the other in the sense that it cannot be effectively decoded except by resources to it".

\section{Justification for the study}

Second language acquisition researchers on writing skill as Halliday and Hassan's work in 1976 (Cohesion in English) highlight the act of creating coherent and cohesive discourse to make sure there is texture or cohesion in writing. The consequence of discourse devices on writing is extremely strong since they offer us with different grammatical devices which are used to broaden any part of discourse to be cohesive. It is important that without having an excellent grasp of the linguistic ties, one cannot construct a cohesive discourse since in traditional grammar the focus is on form not syntax.

Using the Newspaper articles A and B as the foundation, the textual characteristic of meaning by way of cohesion will be studied. In fact, the presupposition is an important aspect in cohesion because it extracts the unrelated sentences by the connected one. Not all aspects of cohesion in the text are noted, but a large part is highlighted to show some examples and how frequently some kinds occur.

\section{Research questions}

4.1 What are the macro-structures of the two texts?

4.2 How is cohesion used to achieve the purpose of the text?

\section{Methodology}

\subsection{Analytical framework}

Using the Newspaper articles Five heart kids need your help (January 2012) and 2 kids need RM68,000 for heart ops (23 December 2011) as the foundation, the textual characteristic of implication through cohesion will be looked into. The doctrine of referencing, conjunction, and lexical cohesion devised by Halliday and Hasan (1976) and Bloor and Bloor (1995) will be utilize on the articles and analyzed to show the significance of the cohesive fundamentals that are available in texts that add to the general implication of the texts. Being aware of how cohesion performs inside text to formulate semantic connections will be useful to aid "decode" meaning. It will focus on the analysis of cohesion devises that are employed in texts, and the level of cohesiveness of the text.

\section{Findings and Discussion}

\subsection{Macrostructure of the texts}

Both the texts start with "summary" in the headlines and the lead, moving to the main story organized as one or more episodes, each consisting of the report of events, followed by consequences and reactions. This macrostructure according to van Dijk (1986), reflects and realizes writers' and readers' cognitive "schema' for both articles, a set of pre-formed expectation about structure and content that simplifies information processing. Each text carries pictures of mother and child. Articles A and B are reports from a main local Newspaper and each article follow the same order when providing details about the children. The writer mentions the age of the children, their names, their heart conditions and descriptions, how urgently the surgery should be carried out and the cost of each child's surgery. Financial background of parents with information on their occupation and salaries are given as well. Details on the number of siblings for each child are also given. Both the texts' organizations are narrative and informative in nature.

\subsection{Structure and Purpose of the texts}

The two articles analysed employ scientific and medical terms to inform readers the serious conditions of the heart patients who are all children. The writers follow the same structure and sequence of reporting the news. The purpose of the texts is to appeal for donation for the children. The writer uses words and phrases like "serious", "emergency", "have another two children", "complicated", "repair", “defects", "tired", “depends", "leakage”, 'deficient", “failure”, 
"life support", "immediate”, "condition", "critical”, and "suffers" to evoke the feelings of the readers and appeal for fund for the children's surgeries.

\subsection{Medical terms used from Article A}

Heart defects, cyanotic congenital heart defect also known as Tetralogy of Fallot, hole in the heart associated with a cleft, which causes a leakage of the mitral valve, deficient leaflet of the mitral valve causes heart to be enlarged which may lead to heart failure, complex congenital heart disease known as supra cardiac total pulmonary venous drainage, where the oxygenated blood returning to the left side of the heart from the lung is channeled to the right side of the heart, ventricular septic defect with a hole between the two lower pumping chambers of the heart and suffers from leakage of the mitral valve.

\subsection{Medical terms from Article B}

Congenital heart lesions, aortic arch, patent ductus arteriosus, ventricular septal defect. hole between the two lower chambers, leakage of the aortic valve

Based on the terms listed above readers need to have some knowledge on the medical terms related to heart failures.

\subsection{Referencing}

Referencing works to regain presupposed information in content and have to be particular for it to be regarded as cohesive. In writing, referencing shows how the writer presents participants and keeps record of them all through the text The three type of referencing are: homophoric referencing, that is shared information by the context of culture, exophoric referencing, which is information from the direct context of circumstances, and endophoric referencing, which is particulars that can be "retrieved" from inside the text. This type of endophoric referencing is the center of cohesion theory. Endophoric referencing is split into three areas: anaphoric, cataphoric, and esphoric. Anaphoric is any reference that "points backwards" to prior information in text. Cataphoric is any reference that "points forward" to information that is stated later on in the text. Esphoric is any reference inside the identical small group or phrase that follows the presupposed item. In term of cohesion foundation, anaphoric referencing is the most pertinent as it "provides a linkage with a preceding portion of the text" (Halliday and Hasan 1976: 51). The three major kinds of cohesive references are: personal, demonstrative, and comparative. Personal reference maintains function through the discourse state with noun pronouns like "she, her, he, him", and possessive determiners like "mine, yours, his, hers". Demonstrative reference maintains information by way of setting using nearness references like "the, this, these, that, those, here, there, and then". Comparative reference maintains identity and likeness by indirect references using adjectives similar to "same, equal, different, else, better, more", and adverbs like "so, such, similarly, otherwise, so, more", etc.

\subsubsection{Texts Analysis -Referencing}

Table 1. Referencing from Articles A and B

\begin{tabular}{|l|l|l|}
\hline & Article A & Article B \\
\hline 1.Personal Referencing & & \\
a. Noun Pronouns & 3 & - \\
he & 2 & 3 \\
she & 1 & 1 \\
they & & \\
b.Posessive determiners & 10 & - \\
his & 4 & 6 \\
her & 1 & 2 \\
their & & \\
\hline 2. Demonstrative & 18 & 7 \\
the & 1 & 1 \\
those & - & 1 \\
these & & 1 \\
here & - & - \\
\hline 3. Comparative & & \\
\hline
\end{tabular}

In article A, there are twenty one occurrences of personal references, nineteen occurrences of demonstrative references, and participants no conjunctive references. When it comes to personal references personal pronouns are used six times and fifteen are possessive determiners. Article be has twelve incidences of personal references of which four are personal pronounce and eight possessive determiners. Articles A uses more references to as the number of children mention in the text is more than article B. Every example recorded in Table 1 is instances of anaphoric reference, the most pertinent type of referencing for cohesion within text. Next, the examples of personal references mentioned are shown as ties to presupposed and take place outside of the referring clause. Halliday shows that this kind of referencing is the most cohesive (Halliday 1994: 312). Personal referencing in text works to take note of partakers all through the text. In article A "His single mother..." refers back to Muhammad Syafiq Saad in line 4. In article B, "She needs surgery...' in line 16, refers back to line 12 to point toward Stephanie Lim. Halliday states demonstrative referencing as "verbal pointing" to denote a "scale of proximity" to the presupposed reference (Halliday and Hasan1976: 57). By 
using "the" as a demonstrative reference, article A has nineteen and article B has seven. The use of "the", generally referred to as a definite article, performs to precisely identify and as a result is "semantically selective". Since the text is written, the references are frequently endophoric which creates a cohesive textual environment. Both the articles do not have comparative referencing.

\subsection{Conjunction}

Conjunction, functions as a cohesive tie among clauses or parts of text in such a way as to demonstrate a significant pattern between them. Therefore, amid the cohesion types of mechanisms in the text, conjunction is the slightest straight forward identifiable connection. Conjunction operates as a semantic cohesive tie in the text in four categories: additive, adversative, causal and temporal. Additive conjunction structurally coordinates by combining to the presupposed item and are indicated with the use of "also, and, too, furthermore, additionally", etc. Additive conjunction can as well function to counteract the presupposed item and is shown by "nor, and...not, either, neither", etc. Adversative conjunctions function are used to show "contrary to expectation" and are indicated by "in fact, though, only, yet, but, rather", etc. Causal conjunction put across "result, reason and purpose" and is indicated by "so, then, for, because, for this reason, as a result, in this respect, etc." Finally, conjunctive category is sequential and connects by indicating series or time. Several example of sequential conjunctive signals are "then, next, after that, next day, at this point", etc.

\subsubsection{Text Analysis}

\section{i. Conjunction}

In article A, there are six entries of conjunction and four in article B. Conjunction performs to connect implication across a wider limit of text. Nevertheless, in these articles, the recovery of conjunctive particular does not require the reader to a long way back in the text to detect the presupposed reference. For instance, in article A line 35, "She also suffers from a leakage of..." links back directly with the heart problem of the child. In article B line 18, “...and earns RM1, 500 per month...", links back to line the child's father. Conjunctions used in both articles explicitly tie the meanings of utterances together, making the meaning of one coordinate with o or subordinate to the meaning of the other. On the whole, despite the fact that conjunction works particularly well to generate cohesion in text, it is not used frequently in the articles.

\section{ii. Lexical Cohesion}

A group of words is lexically cohesive when all of the words are semantically related; for example, when they all concern the same topic. Lexical cohesion is non-grammatical. Lexical cohesion signifies the cohesive effect attained by the choice of vocabulary. Reiteration and collocation are the two types of lexical cohesion. Reiteration relates to the repetition of a lexical item. Collocation relates to lexical items that are probably discovered jointly within the same text. Collocation takes place when two words are not essentially dependent upon the indistinguishable semantic connection but to a certain extent they are inclined to take place in the same lexical environment. The closer the lexical items are placed among sentences, the powerful the cohesive outcome.

\section{iii. Text Analysis- Lexical Cohesion}

It is important to note that whether it is diverse modes of reiteration or through collocation, a obviously identifiable selection of lexical plan is exceptionally obvious in articles A and B. Cohesion can be viewed clearly, as both the texts project conjunctions which explicitly tie the meanings of sentences together, making the meaning of one coordinate with or subordinate forming a pattern of chains or a network. We need to consider which patterning is suitable in the case of lexical cohesion.

\subsection{Reiteration}

In reiteration a lexical item is repeated although the repetition might not accurately correspond with the presupposed lexical item. Reiteration can be in the mode of repetition of the identical word or by means of a synonym, antonym, meronym, or hyponym.

\subsubsection{Analysis}

\section{Article A}

"The (1) oxygenated blood returning to the (2) left side of the (3) heart from the (4) lungs is channeled to the (5) right side of the (6) heart.'(lines 26-27)"

\section{Article B}

"She needs surgery to repair the defect and prevent the damage to the aortic valve from progressing."

Here we find repetition chain where the article 'the' is mention six times in the sentence in article A and three times in article $\mathrm{B}$ to show cohesion.

\subsubsection{Collocation}

Collocation is the inclination of words to "share the same lexical environment" (Halliday and Hasan 1976: 286). Collocation denotes the semantic and structural relation amid words, which native speakers can use unintentionally for understanding or creation of a text. Below are samples of collocations from article A and article B respectively. 


\section{Article A}

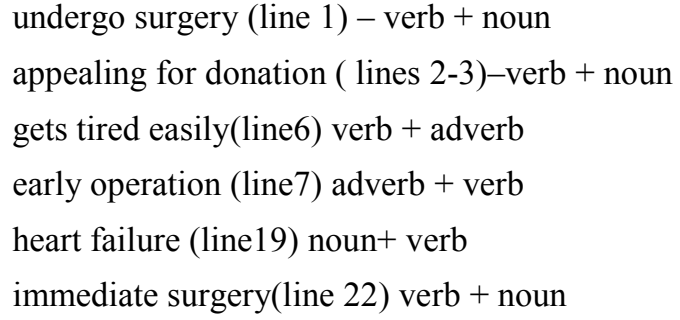

\section{Article B}

$$
\begin{aligned}
& \text { serious condition ( lines 2-3) adjective + noun } \\
& \text { emergency case (line 7) noun }+ \text { noun } \\
& \text { undergo an operation (line } 8 \text { ) verb }+ \text { noun } \\
& \text { estimated cost (line 17) noun }+ \text { noun }
\end{aligned}
$$

\subsubsection{Analysis}

The lexical patterns established are conveyed and is identified to be a collocation related to the problem of the victims' heart. By means of the lexical cohesion study of these articles, a very rigid pattern of cohesion was discovered. Repetition due to identical lexical items and collocation is prevailing and generates what Halliday and Hasan describe texture in text.

\section{Conclusion}

Cohesion investigations have verified what theory is present to construct semantic links within text involving sentences and paragraphs. Based on article A and article B, cohesion in texts produces one class of texture through the ties that create together initiatives and experiences and texture creates meaning within language. Newspapers provide one of the most powerful vehicles for comparison in modern society. It could be argued that headlines and contents in both articles because of their diffusion and visual and linguistic impact - play a key role in maintaining the constant presence of information and representations in our daily lives.

\section{References}

Brown, Gillian \& George Yule. (1989) Discourse Analysis. Cambridge: Cambridge University Press.

Hoey, M. (2001) Textual Interaction: An Introduction to Written Discourse Analysis; Oxford:Routledge.

Halliday, M.A.K. and Hasan, R. (1976). Cohesion in English London: Longman

Halliday, M.A.K. (1994) Introduction to Functional Grammar London, New York, etc: Arnold

Gee, J. P. (2006) An introduction to Discourse analysis: Theory and method, 2nd edition. New York:Routledge

Grimes, Joseph E. (1975) The Thread of Discourse. The Hague: Mouton.

Fellbaum, C. (ed) (1998) WordNet: An Electronic Lexical Database, MIT Press.

Fellbaum, C. et al (1993) 5 Papers on Wordnet.www.cogsci.princeton.edu/ wn/

Ferret, O. (2002) Using collocations for topic segmentation and link detection. In S.-C. Tseng, T.-E. Chen \& Y.-F. Liu (Eds.), Proceedings of the $19^{\text {th }}$ International Conference on Computational Linguistics. Taipei, Taiwan, August 24September 1.

Firth, J.R. (1957). A synopsis of Linguistic Theory, 1930-1955. Studies in Linguistic Analysis,1-31. London: Blackwell. Halliday, MAK and Hasan, R. (1976) Cohesion in English. London: Longman.

Halliday, MAK and J.R Martin (1993). Writing Science. Literary and Discursive Power. London: The Falmer Press Johnstone, Barbara (2008) Discourse Analysis. Blackwell Publishing.

Lyons, J. (1977) Semantics, Vol 1. Cambridge: Cambridge University Press

Lyons, J. (1986) Introduction to Theoretical Linguistics. Cambridge: Cambridge University Press (chapter 10.1-10.4)

Martin, J.R.( 1992) English text: system and structure. Amsterdam: Benjamins (chapter 5)

Nunan, David. (1993) Introducing Discourse analysis. New York: Penguin English.

Titscher, Stefan, et al. (2000) Method of Text and Discourse analysis. London: SAGE Publications.

Van Dijk, T.A. (1986) News schemata. In C.R.Cooper and S. Greenbaun (eds.), Studying Writing: Linguistic approaches, Beverly Hills, CA: Sage. 